\title{
Mathematical model of potato slices under process-based temperature and humidity integration control of tilted tray air impingement drying
}

\author{
DAI JIAN WU ${ }^{1, a}$, WANG JIE ${ }^{1, a}$, REN LING ${ }^{1,}$, , LIU YAO WEN ${ }^{1, a}$ and ZHANG LI \\ $\operatorname{HUA}^{1, a}$
}

${ }^{1}$ College of Mechanical and Electrical Engineering, Sichuan Agricultural University, 625014, Ya'An, Sichuan Province, China

${ }^{2}$ College of Food Science, Sichuan Agricultural University, 625014, Ya'An, Sichuan Province, China

adaijianwu@126.com, b364720874@qq.com

Keywords: potato slices, mathematical model, air impingement drying, integration control

Abstract. Mathematical model of potato slices under process-based temperature and humidity integration control of tilted tray air impingement drying were investigated under different parameters. Results indicated that the Weibull distribution function simulated the drying curves of potato slices under PDTHIC drying well. The coefficient of determination ranged from 0.989 to 0.999 , the root mean square error was in the range of $1.04 \times 10^{-2}$ to $2.57 \times 10^{-2}$, and the derivate square ranged from $1.25 \times 10^{-4}$ to $7.15 \times 10^{-4}$. The scale parameter $\alpha$ is related to both the humidity control parameters during the earlier stage and the medium stage. The shape parameter $\beta$ decreased in the range of 0.811 0.964 with the increase of constant humidity, whereas fluctuated in the range of $0.836 \sim 0.987$ and had no regulations with the changing of the values of humidity control time. The estimated moisture effective diffusivity of potato slices under different drying conditions calculated by scale parameter $\alpha$ ranged from $1.664 \times 10^{-9} \mathrm{~m}^{2} \cdot \mathrm{s}^{-1}$ to $2.371 \times 10^{-9} \mathrm{~m}^{2} \cdot \mathrm{s}^{-1}$, and the values of geometric parameters $\mathrm{R}_{\mathrm{g}}$ was calculated in a fluctuant way in the range of 2.575 5.351.

\section{Introduction}

The drying model is a mathematical abstraction for describing the drying process and further revealing the regulations of drying parameters during the dehydration of material. The setup of drying model can provide the technical basis for describing, predicting, analyzing, controlling and optimizing of material drying process. Recently, some empirical and semi-empirical models have been already widely applied to the expression of drying process, such as Lewis, Page, Modified Page, Wang and Singh, Logarithmic, Two-order experimental model and Two-order exponential model, etc. Although these models can extremely simulate the curves of drying kinetics with a high accuracy, the practical guiding significance of parameters in the models are still indefinite, and both the materials properties and drying conditions are difficult to relate to the parameters of these models used. Hence, the whole process is still considered as a black box. These drying models can't be closely related to the drying technology, drying efficiency and heat transfer process, greatly limiting the application value and research significance.

Recently the Weibull model has been widely applied to the field of biological sterilization, pharmacology, thermodynamics and food engineering due to its application and compatibility. Rong-Rong Lu et al. ${ }^{[1]}$ published spore death curves under ultra-high pressure sterilization condition using the Weibull model. Boekel ${ }^{[2]}$ studied the Weibull model to describe the thermal inactivation characteristics of microbial cells. Recent years, some researchers have used the Weibull model for analyzing drying characteristics of agricultural products and obtained research progress. Corzo et al. ${ }^{[3]}$ studied the Weibull distribution for fitting curves of hot air drying of mango slices. Bai et al. ${ }^{[4]}$ used the Weibull distribution function to describe the drying kinetic characteristics of grapes. But as a whole, the relative reports about process-based drying temperature and humidity integration control air impingement model of high-starch materials have not been reported yet.

In this paper, the objectives of current work were to focus on microwave intermittent drying kinetics of banana slices. Then the quality of fitting was determined according to the statistical 
parameters such as the correlation coefficient $\left(\mathrm{R}^{2}\right)$, root mean square error (RMSE) and derivate square $\left(\chi^{2}\right)$. And the final objectives was to illustrate the physical significance of the parameters in drying process, to provide a kind of operational tool for predicting, controlling, analyzing high-starch materials in optimization of drying technology.

\section{Materials and methods}

\section{Raw material}

Fresh potatoes (Yanshu NO.4) were purchased from an agricultural wholesale market in Beijing. Potatoes of equal size were selected as raw materials. The initial moisture content of the potato samples was $3.9 \mathrm{~g} / \mathrm{g}$ in dry basis. The prepared samples were wrapped with a plastic film and stored in a refrigerator at $5 \pm 1^{\circ} \mathrm{C}$ prior to the experiments.

\section{Experimental set-up and procedure}
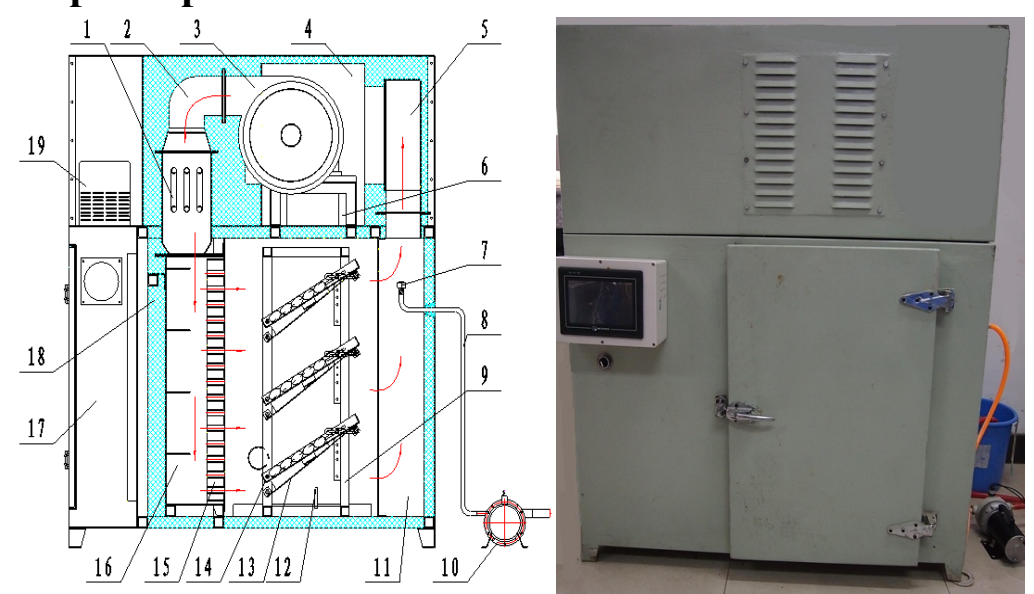

Fig. 1 Schematic diagram for process-based temperature and humidity integration control of tilted tray air impingement dryer

The fresh potatoes were washed to remove the dust, and then wiped with gauze to eliminate excess water on its surface. The samples were cut into slices with different thickness using a kitchen cutter. Each sample was located so as not to touch the adjacent ones. Weigh the samples on an electronic balance at $1 \mathrm{~h}$ intervals during drying. Drying process was continued until the potato slices reached the desired final moisture content of $14 \%$ (w.b.) or $0.16 \mathrm{~kg} / \mathrm{kg}$ (d.b.). The temperature and velocity of airflow were kept at $60^{\circ} \mathrm{C}$ and $15 \mathrm{~m} / \mathrm{s}$, respectively. In addition, the samples were pretreated with hot water blanching under $90^{\circ} \mathrm{C}$ for $60 \mathrm{~s}$ so as to keep partial enzyme activity, with the subsequent objective of actually finding the effects of the PDTHIC technology on color protection. The relative humidity of surroundings was measured with $17 \%$ RH. All experiments were performed in triplicate as shown in Table 1.

Table 1 Design for experiments with drying parameters included

\begin{tabular}{|c|c|c|c|c|c|c|}
\hline \multirow{2}{*}{ NO. } & \multicolumn{2}{|c|}{ Drying at earlier stage } & \multicolumn{2}{|c|}{ Drying at medium stage } & \multicolumn{2}{|c|}{ Drying at later stage } \\
\hline & $\begin{array}{c}\text { Humidity/\%R } \\
\text { H }\end{array}$ & Time/h & $\begin{array}{c}\text { Humidity/\%R } \\
\text { H }\end{array}$ & Time/h & $\begin{array}{c}\text { Humidity/\% } \\
\text { RH }\end{array}$ & Time/h \\
\hline 1 & $\begin{array}{l}\text { 10(continuous } \\
\text { dehumidificati } \\
\text { on) }\end{array}$ & --- & --- & --- & --- & --- \\
\hline 2 & 20 & --- & --- & --- & --- & --- \\
\hline 3 & 30 & --- & --- & --- & --- & --- \\
\hline 4 & 40 & --- & --- & --- & --- & --- \\
\hline 5 & 50 & --- & --- & --- & --- & --- \\
\hline 6 & 50 & 1 & 10 & --- & --- & --- \\
\hline 7 & 50 & 2 & 10 & --- & --- & --- \\
\hline 8 & 50 & 3 & 10 & --- & --- & --- \\
\hline
\end{tabular}




\begin{tabular}{|c|c|c|c|c|c|c|}
\hline 9 & 50 & 4 & 10 & --- & --- & --- \\
\hline 10 & 50 & 5 & 10 & --- & --- & --- \\
\hline 11 & 20 & 2 & 10 & --- & --- & --- \\
\hline 12 & 30 & 2 & 10 & --- & --- & -- \\
\hline 13 & 40 & 2 & 10 & --- & --- & -- \\
\hline 14 & 50 & 2 & 30 & 1 & 10 & --- \\
\hline 15 & 50 & 2 & 30 & 2 & 10 & --- \\
\hline 16 & 50 & 2 & 30 & 3 & 10 & --- \\
\hline 17 & 50 & 2 & 30 & 4 & 10 & --- \\
\hline
\end{tabular}

\section{Calculation of moisture effective diffusivity Mathematical modeling of drying curves}

Drying curves of potato slices were fitted with Weibull model (Eq. (1) $)^{[5]}$.

$M R=\exp \left[-\left(\frac{t}{\beta}\right)^{\alpha}\right]$.

Where $t$ is the drying time, $\alpha$ is the shape parameter of the Weibull model, and $\beta$ is the scale parameter of the model.

The moisture ratio (MR) of potato slices during drying experiments was calculated with a more simplified form as follows ${ }^{[6]}$ :

$$
M R=\frac{M_{t}}{M_{o}} .
$$

Where $\mathrm{M}_{0}$ is the initial moisture content of potato slices, $\mathrm{M}_{\mathrm{t}}$ is the moisture content at time $\mathrm{t}$.

The drying rate of sample slices during drying experiments was computed using Eq. (3) ${ }^{[7]}$ :

$$
D R=\frac{M_{t_{1}}-M_{t_{2}}}{t_{2}-t_{1}} \text {. }
$$

Where $t_{1}$ and $t_{2}$ is the drying time at different moment respectively during drying with expression in hours; $M_{t 1}$ and $M_{t 2}$ is the moisture content of samples at $t_{1}$ and $t_{2}, g \cdot g^{-1}$.

The natural logarithm form of moisture effective diffusivity was determined as shown in Eq. (4) ${ }^{[8]}$ :

$$
\ln (M R)=\ln \left(\frac{6}{\pi^{2}}\right)-\left(\pi^{2} \frac{D_{e f f} t}{r_{o}^{2}}\right) \text {. }
$$

There is a linear relationship between the natural logarithm of moisture ratio and drying time of sample slices according to Eq. (4). However, this equation does not apply to the products with acceleration sections in the drying process. Hence, it is significant for Weibull model to evaluate the effective moisture diffusivity without considering the moisture movement properties. In this model, $D_{\text {eff }}$ can be determined as shown in Eq. $(5)^{[9]}$ :

$$
D_{\text {eff }}=\frac{D_{c a l}}{R_{g}}=\frac{r^{2}}{\beta R_{g}} \text {. }
$$

Where $\mathrm{D}_{\text {cal }}$ is the estimate moisture diffusivity $\left(\mathrm{m}^{2} \cdot \mathrm{s}^{-1}\right) ; \mathrm{r}$ is the volume equivalent radius of potato samples, with $1.59 \times 10^{-2} \mathrm{~m}$ as its value; $\beta$ is the scale parameter of Weibull model; $\mathrm{R}_{\mathrm{g}}$ is the physical dimension constant with $18.6 \mathrm{~m}^{2} \cdot \mathrm{s}^{-1}$ for sphere material ${ }^{[10]}$. 


\section{Results and discussion}

\section{Mathematical modeling of drying kinetics with Weibull distribution function}

Table 2 Design for experiments with drying parameters included

\begin{tabular}{|c|c|c|c|c|c|c|}
\hline Drying method & Humidity parameter & $\begin{array}{c}\text { Scale } \\
\text { parameter } \\
\beta / \mathrm{min}\end{array}$ & $\begin{array}{c}\text { Shape } \\
\text { parameter } \\
\alpha \\
\end{array}$ & $\begin{array}{c}\text { coefficient } \\
\text { of } \\
\text { determinati } \\
\mathrm{R}^{2} \\
\end{array}$ & $\begin{array}{c}\text { root mean } \\
\text { square } \\
\text { error } \\
\text { RMSE }\end{array}$ & $\begin{array}{c}\text { derivate } \\
\text { square } \chi^{2}\end{array}$ \\
\hline \multirow{5}{*}{$\begin{array}{c}\text { Different } \\
\text { constant } \\
\text { humidity }\end{array}$} & $10 \% \mathrm{RH}$ constant humidity & 175.722 & 0.884 & 0.996 & $1.69 \times 10^{-2}$ & $3.28 \times 10^{-4}$ \\
\hline & $20 \% \mathrm{RH}$ constant humidity & 210.528 & 0.964 & 0.997 & $1.59 \times 10^{-2}$ & $2.86 \times 10^{-4}$ \\
\hline & $30 \% \mathrm{RH}$ constant humidity & 197.040 & 0.942 & 0.999 & $1.04 \times 10^{-2}$ & $1.25 \times 10^{-4}$ \\
\hline & $40 \% \mathrm{RH}$ constant humidity & 219.882 & 0.875 & 0.996 & $1.67 \times 10^{-2}$ & $3.14 \times 10^{-4}$ \\
\hline & $50 \% \mathrm{RH}$ constant humidity & 240.186 & 0.811 & 0.989 & $2.57 \times 10^{-2}$ & $7.15 \times 10^{-4}$ \\
\hline \multirow{6}{*}{$\begin{array}{c}\text { Different } \\
\text { humidity control } \\
\text { time at initial } \\
\text { stage }\end{array}$} & $10 \% \mathrm{RH}$ constant humidity & 175.722 & 0.884 & 0.996 & $1.69 \times 10^{-2}$ & $3.28 \times 10^{-4}$ \\
\hline & Initial stage $50 \%$ RH $1 \mathrm{~h}$ & 215.682 & 0.885 & 0.998 & $1.14 \times 10^{-2}$ & $1.49 \times 10^{-4}$ \\
\hline & Initial stage $50 \%$ RH $2 \mathrm{~h}$ & 200.280 & 0.987 & 0.998 & $1.42 \times 10^{-2}$ & $2.35 \times 10^{-4}$ \\
\hline & Initial stage $50 \%$ RH $3 \mathrm{~h}$ & 204.336 & 0.912 & 0.995 & $1.98 \times 10^{-2}$ & $4.46 \times 10^{-4}$ \\
\hline & Initial stage $50 \% \mathrm{RH} 4 \mathrm{~h}$ & 213.744 & 0.836 & 0.996 & $1.68 \times 10^{-2}$ & $3.15 \times 10^{-4}$ \\
\hline & Initial stage $50 \% \mathrm{RH} 5 \mathrm{~h}$ & 223.158 & 0.897 & 0.994 & $2.07 \times 10^{-2}$ & $4.74 \times 10^{-4}$ \\
\hline \multirow{5}{*}{$\begin{array}{c}\text { Different } \\
\text { humidity control } \\
\text { humidity at } \\
\text { initial stage }\end{array}$} & $10 \% \mathrm{RH}$ constant humidity & 175.722 & 0.884 & 0.996 & $1.69 \times 10^{-2}$ & $3.28 \times 10^{-4}$ \\
\hline & Initial stage $20 \% \mathrm{RH} 2 \mathrm{~h}$ & 250.374 & 0.876 & 0.998 & $1.26 \times 10^{-2}$ & $1.81 \times 10^{-4}$ \\
\hline & Initial stage $30 \% \mathrm{RH} 2 \mathrm{~h}$ & 197.856 & 0.860 & 0.996 & $1.60 \times 10^{-2}$ & $2.87 \times 10^{-4}$ \\
\hline & Initial stage $40 \%$ RH $2 \mathrm{~h}$ & 188.994 & 0.966 & 0.997 & $1.51 \times 10^{-2}$ & $2.63 \times 10^{-4}$ \\
\hline & Initial stage $50 \%$ RH $2 \mathrm{~h}$ & 200.280 & 0.987 & 0.998 & $1.42 \times 10^{-2}$ & $2.35 \times 10^{-4}$ \\
\hline \multirow{5}{*}{$\begin{array}{c}\text { Different } \\
\text { humidity control } \\
\text { time at medium } \\
\text { stage }\end{array}$} & Initial stage $50 \%$ RH $2 \mathrm{~h}$ & 200.280 & 0.987 & 0.998 & $1.42 \times 10^{-2}$ & $2.35 \times 10^{-4}$ \\
\hline & Medium stage $30 \% \mathrm{RH} 1 \mathrm{~h}$ & 219.282 & 0.887 & 0.996 & $1.63 \times 10^{-2}$ & $3.00 \times 10^{-4}$ \\
\hline & Medium stage $30 \%$ RH $2 \mathrm{~h}$ & 217.812 & 0.932 & 0.997 & $1.53 \times 10^{-2}$ & $2.74 \times 10^{-4}$ \\
\hline & Medium stage $30 \% \mathrm{RH} 3 \mathrm{~h}$ & 218.946 & 0.956 & 0.996 & $1.69 \times 10^{-2}$ & $3.32 \times 10^{-4}$ \\
\hline & Medium stage $30 \%$ RH $4 \mathrm{~h}$ & 241.368 & 0.909 & 0.996 & $1.68 \times 10^{-2}$ & $3.17 \times 10^{-4}$ \\
\hline
\end{tabular}

The results of potato slices under different drying conditions were simulated by Weibull function and presented in Tab.2. From Tab.2, it can be seen that the coefficient of determination $\mathrm{R}^{2}$ ranged from 0.989 to 0.999 , the root mean square error (RMSE) was in the range of $1.04 \times 10^{-2}$ to $2.57 \times 10^{-2}$, and the derivate square $\left(\chi^{2}\right)$ changed from $1.25 \times 10^{-4}$ to $7.15 \times 10^{-4}$. Hence, the simulation results showed that the Weibull distribution function was suitable for matching the drying kinetic curves of potato slices under different drying conditions, which provided the subsequent basis for analyzing the drying process with mathematical model.

(1) Physical significance and influential factors of scale parameter $\alpha$

As for the whole drying process of potato slices, the scale parameter $\alpha$ in the Weibull model meant the rate constant of the drying process. And its value concretely represented the time needed for removal approximately $63 \%$ of the samples moisture content during the entire dehydration process. According to Tab.2, when the air humidity in the drying chamber rose from $10 \% \mathrm{RH}$ (continuous dehumidification) to $50 \% \mathrm{RH}$ with the hot-air velocity of $15 \mathrm{~m} \cdot \mathrm{s}^{-1}$ at $60^{\circ} \mathrm{C}$, the scale parameter gradually increased from $175.722 \mathrm{~min}$ to $240.186 \mathrm{~min}$ in a fluctuant way. It illustrated that the drying efficiency gradually slowed down with the rose of drying humidity. At the same time, the value of $\alpha$ accounted for $19.52 \%, 21.93 \%, 24.33 \%, 21.56 \%$ and $16.01 \%$ of the total drying time of potato slices, respectively. The results indicated that the dehydration process during the later stage had taken up most of the whole drying time. Therefore, it's very important to adjust the process conditions according to the value of scale parameter. And the obtain of scale parameter $\alpha$ had practical guiding significance on the optimization of drying process, which can be calculated by fitting analysis on partial experiment data in a short time. 
As the humidity control time of $50 \% \mathrm{RH}$ in the earlier stage increased from $0 \mathrm{~h}$ (continuous dehumidification) to $5 \mathrm{~h}$, the value of $\alpha$ rose oscillatorily from 175.722 to $223.158 \mathrm{~min}$. The minimum value during the humidity control trials was got under the earlier stage with control time at $2 \mathrm{~h}$, and its time for removal $63 \%$ of the samples moisture content also accounted for the highest level of the whole drying time. This illustrated that the drying time under the above drying condition was much shorter than others. Further, as the value of control humidity increased from $20 \% \mathrm{RH}$ to $50 \% \mathrm{RH}$ during the earlier stage for both $2 \mathrm{~h}$, the scale parameter fluctuated from 175.7 to $250.4 \mathrm{~min}$. Although the time for removal $63 \%$ of moisture content accounted for the highest level of the whole drying time at $20 \% \mathrm{RH}$ for $2 \mathrm{~h}$ during the earlier stage, the scale parameter $\alpha$ still got the maximum value. As a result, the total drying time under this condition was not the shortest one due to the above comprehensive influences.

(2) Physical significance and influencing factors of shape parameter $\beta$

The shape parameter $\beta$ is a dimensionless constant closely related to kinetic curves during material drying process. Combining graphical distribution characteristic and changing regulations, the effect of the shape parameter $\beta$ on the material drying condition and analysis of changing trend can be intuitively understood.

According to Tab.2, the values of shape parameter $\beta$ constantly decreased in the range of 0.811 0.964 with the increase of constant humidity (except constant dehumidification controlled trial), whereas the values of shape parameter $\beta$ fluctuated in the range of $0.836 \sim 0.987$ and had no regulations with the changing of the values of humidity control time and humidity at earlier stage and humidity control time at medium stage. This probably due to the fact that the shape parameter $\beta$ is a parameter related to drying methods, thus the effect of drying temperature and humidity on $\beta$ was slight for the same drying materials.

Analysis of moisture effective diffusivity

Table 3 Moisture effective diffusivity of potato slices during drying process

\begin{tabular}{|c|c|c|c|c|}
\hline Drying method & Humidity parameter & $\begin{array}{c}\text { Estimated } \\
\text { moisture effective } \\
\text { diffusivity } D_{\text {cal }} \\
\left(10^{-9} \mathrm{~m}^{2} / \mathrm{s}\right)\end{array}$ & $\begin{array}{l}\text { Moisture effective } \\
\text { diffusivity } D_{\text {eff }} \\
\quad\left(10^{-10} \mathrm{~m}^{2} / \mathrm{s}\right)\end{array}$ & $\begin{array}{c}\text { Geometric } \\
\text { parameter Rg }\end{array}$ \\
\hline \multirow{5}{*}{$\begin{array}{l}\text { Different constant } \\
\text { humidity }\end{array}$} & $\begin{array}{l}10 \% \mathrm{RH} \text { constant humidity } \\
\text { (continuous dehumidification) }\end{array}$ & 2.371 & 6.120 & 3.874 \\
\hline & $20 \%$ RH constant humidity & 1.979 & 5.816 & 3.403 \\
\hline & $30 \% \mathrm{RH}$ constant humidity & 2.115 & 6.717 & 3.148 \\
\hline & $40 \% \mathrm{RH}$ constant humidity & 1.895 & 5.157 & 3.675 \\
\hline & $50 \%$ RH constant humidity & 1.735 & 3.242 & 5.351 \\
\hline \multirow{6}{*}{$\begin{array}{l}\text { Different humidity } \\
\text { control time at initial } \\
\text { stage }\end{array}$} & $\begin{array}{l}10 \% \mathrm{RH} \text { constant humidity } \\
\text { (continuous dehumidification) }\end{array}$ & 2.371 & 6.120 & 3.874 \\
\hline & Initial stage $50 \% \mathrm{RH} 1 \mathrm{~h}$ & 1.932 & 5.876 & 3.288 \\
\hline & Initial stage $50 \% \mathrm{RH} 2 \mathrm{~h}$ & 2.080 & 7.751 & 2.684 \\
\hline & Initial stage $50 \% \mathrm{RH} 3 \mathrm{~h}$ & 2.039 & 5.664 & 3.600 \\
\hline & Initial stage $50 \% \mathrm{RH} 4 \mathrm{~h}$ & 1.949 & 4.934 & 3.951 \\
\hline & Initial stage $50 \% \mathrm{RH} 5 \mathrm{~h}$ & 1.867 & 4. 488 & 4.160 \\
\hline \multirow{5}{*}{$\begin{array}{l}\text { Different humidity } \\
\text { control humidity at } \\
\text { initial stage }\end{array}$} & $\begin{array}{l}10 \% \mathrm{RH} \text { constant humidity } \\
\text { (continuous dehumidification) }\end{array}$ & 2.371 & 6.120 & 3.874 \\
\hline & Initial stage $20 \% \mathrm{RH} 2 \mathrm{~h}$ & 1.664 & 6.464 & 2.575 \\
\hline & Initial stage $30 \% \mathrm{RH} 2 \mathrm{~h}$ & 2.106 & 5.289 & 3.982 \\
\hline & Initial stage $40 \% \mathrm{RH} 2 \mathrm{~h}$ & 2.205 & 6.829 & 3.228 \\
\hline & Initial stage $50 \% \mathrm{RH} 2 \mathrm{~h}$ & 2.080 & 7. 751 & 2.684 \\
\hline \multirow{5}{*}{$\begin{array}{l}\text { Different humidity } \\
\text { control time at } \\
\text { medium stage }\end{array}$} & Earlier stage $50 \%$ RH $2 \mathrm{~h}$ & 2.080 & 7. 751 & 2.684 \\
\hline & Medium stag $30 \%$ RH $1 \mathrm{~h}$ & 1.900 & 5.420 & 3.506 \\
\hline & Medium stage $30 \%$ RH $2 \mathrm{~h}$ & 1.913 & 6.960 & 2.749 \\
\hline & Medium stage $30 \%$ RH $3 \mathrm{~h}$ & 1.903 & 6.190 & 3.074 \\
\hline & Medium stage $30 \% \mathrm{RH} 4 \mathrm{~h}$ & 1.726 & 5. 167 & 3.340 \\
\hline
\end{tabular}


Geometric parameter $\mathrm{R}_{\mathrm{g}}$ is a constant having nothing to do with the moisture effective diffusivity. Potato slices having the thickness of $10 \mathrm{~mm}$ were selected in the experiments; thereby they can be regarded as flat materials. During the temperature and humidity integration control experiments, $\mathrm{R}_{\mathrm{g}}$ values under different constant humidity fluctuated in the range of 3.148 5.35; $\mathrm{R}_{\mathrm{g}}$ values ranged from 2.684 to 4.160 with the increase of humidity control time with $50 \% \mathrm{RH}$ at earlier stage; $\mathrm{R}_{\mathrm{g}}$ values changed slightly in the range of 2.575 3.982 with the increase of humidity control humidity during humidity control of $2 \mathrm{~h}$ at earlier stage; after humidity control for $2 \mathrm{~h}$ with $50 \% \mathrm{RH}$ at earlier stage, $\mathrm{R}_{\mathrm{g}}$ values changes slightly in the range of 2.684 3.506 with the increase of humidity control time with $30 \%$ RH at medium stage.

\section{Conclusions}

The Weibull distribution function simulated the drying curves of potato slices PDTHIC air impingement drying well. The coefficient of determination ranged from 0.989 to 0.999 , the root mean square error was in the range of $1.04 \times 10^{-2}$ to $2.57 \times 10^{-2}$, and the derivate square ranged from $1.25 \times 10^{-4}$ to $7.15 \times 10^{-4}$.

The scale parameter $\alpha$ is related to both the humidity control parameters during the earlier stage and the medium stage. In the condition of the drying temperature of $60^{\circ} \mathrm{C}$ and the wind speed of $15 \mathrm{~m} / \mathrm{s}$, with the increase of constant humidity with $10 \% \mathrm{RH}$ to $50 \% \mathrm{RH}$ and the humidity control holding time with $50 \% \mathrm{RH}$ in the earlier stage of the drying process from $0 \mathrm{~h}$ to $5 \mathrm{~h}$, the values of the scale parameter $\alpha$ increased in a fluctuant way within the range of $175.722 \mathrm{~min}$ to $240.186 \mathrm{~min}$; whereas the effect of humidity control of $2 \mathrm{~h}$ under different humidity at earlier stage and humidity control time at medium stage on the values of $\alpha$ was of no significance, presenting a fluctuant changing rule. The shape parameter $\beta$ constantly decreased (except constant dehumidification controlled trial) in the range of 0.811 0.964 with the increase of constant humidity, whereas the values of shape parameter $\beta$ fluctuated in the range of $0.836 \sim 0.987$ and had no regulations with the changing of the values of humidity control time.

The estimated moisture effective diffusivity of potato slices under different drying conditions calculated by scale parameter $\alpha$ ranged from $1.664 \times 10^{-9} \mathrm{~m}^{2} \cdot \mathrm{s}^{-1}$ to $2.371 \times 10^{-9} \mathrm{~m}^{2} \cdot \mathrm{s}^{-1}$ coinciding with the changing trend of $D_{\text {eff, }}$, and the values of geometric parameters $\mathrm{R}_{\mathrm{g}}$ was calculated in a fluctuant way in the range of 2.575 5.351 during drying based on humidity and temperature integration control.

\section{Acknowledgements}

This work was financially supported by the Science Technology Project of Sichuan (Grant No. 17ZB0331) and Natural Science Foundation of Sichuan (Grant No. 035Z1986).

\section{References}

[1] Lu, R.R. Kinetic model baroduric bacteria in foods low in acid in the processing of ultral-high pressure killing. Transactions of the CSAE, 20 (9): 45 49. (2010)

[2] Gemma O., Isabel O.S., Robert S.F., et al. Using of Weibull distribution for describing kinetics of antioxidant potential changes in fresh-cut watermelon. Journal of Food Engineering, 95, 99 105. (2009)

[3] Corzo, O.; Bracho, N.; Pereira, A.; Vasquez, A. Weibull distribution for modeling air drying of coroba slices. LWT - Food Science and Technology, 41, 2023-2028. (2008)

[4] Bai, J.W.; Wang, J.L.; Xiao, H.W.; Ju, H.Y.; Liu, Y.H.; Gao, Z.J. Weibull distribution for modeling drying of grapes and its application. Transactions of the Chinese Society of Agricultural Engineers 29, 278-285. (2013) 
[5] Jin,Z.Q; W,S.X; H,P. Kinetic model of aspergillus parasiticus in the processing of microwave killing enzyme in moldy corns. Transactions of the Chinese Society of Agricultural Machinery, 11(12): 148 153. (2011)

[6] Li B., Lu F., Liu B. G. Microwave-vacuum drying characteristics and process optimization of agaricus bisporus slices. Transactions of the CSAE, 26(6): 380-384. (2010)

[7] Cunha, L.M.; Oliverira, F.A.R.; Aboim, A.P.; Frias, J.M.; PinheiroTorres, A. Stochastic approach to the modeling of water losses during osmotic dehydration and improved parameter estimation. International Journal of Food Science and Technology, 36, 253-262. (2011)

[8] Miranda, M.; Vega-Galvez, A.; Garcia, P.; Di Scala, K.; Shi, J.; Xue, S.; Uribe, E. Effect of temperature on structural properties of aloe vera (Aloe barbadensis Miller) gel and Weibull distribution for modeling drying process. Food and Bio-products Processing, 88, 138-144. (2012)

[9] Huang Y., Huang J. L., Zheng B. D. Microwave vacuum drying properties and kinetics model of white fungus. Transactions of the CSAE, 26(4): 362-367. (2010)

[10] Martinus A.J.S. van Boekel. On the use of Weibull model to describe thermal inactivation of microbial vegetative cells. International Journal of Food Microbiology, 74, 139 159. (2009) 